\title{
Fixed Point Theorems In Dislocated Quasi-Metric Spaces
}

\author{
I. Ramabhadra Sarma ${ }^{1}$, J. Madhusudana Rao ${ }^{2}$ and S. Sambasiva Rao ${ }^{3, *}$ \\ ${ }^{1}$ Department of Mathematics, Acharya Nagarjuna University, Nagarjuna Nagar, Guntur, Andhra Pradesh, India \\ ${ }^{2}$ Vijaya Engineering College, Wyra Road, Khammam-507305, Andhra Pradesh, India \\ ${ }^{3}$ Department of Humanities and Basic Sciences, SVS Institute of Technology, Bheemaram,Hasanparthy, Warangal, Andhra Pradesh- \\ 506015, India
}

Received: 13 Jun. 2013, Revised: 9 Oct. 2013, Accepted: 10 Oct. 2013

Published online: 1 Jan. 2014

\begin{abstract}
Some interesting properties of dislocated quasi-metric are obtained. Using these properties some fixed point theorems for contractions and Kannan mappings are derived dropping continuity condition imposed by F. M. Zeyada et al (The Arabian Journal for Science and Engineering, Volume 31, Number 1A, (2005), 111-114), C. T. Aage and J. N. Salunke (Applied Mathematical Sciences, Vol. 2,59 (2008) 2941-2948).
\end{abstract}

Keywords: Dislocated quasi-metric space, dislocated metric, fixed point, contractions, Kannan mapping

\section{Introduction}

The notion of Dislocated quasi-metric space has been introduced by F.M. Zeyada et al and proved a version of Banach Contraction principle in such spaces(see [5]). In [4] C.T. Aage and J. N. Salunke proved dislocated quasi-metric version of Kannan mapping theorem. In this paper we present some interesting properties of dislocated quasi-metric spaces. Using these properties some fixed point theorem for contractions and Kannan mappings are derived dropping continuity condition imposed by F.M. Zeyada and C.T. Aage.

In what follows $\mathbb{N}, \mathbb{R}, \mathbb{Q}$ denote the sets of natural, real and rational numbers respectively.

Definition 1.[5] Let $X$ be a nonempty set and $d: X \times X \rightarrow$ $[0, \infty)$ satisfy the following conditions:

(d1) $d(x, y)=d(y, x)=0$ implies $x=y$,

(d2) $d(x, y) \leq d(x, z)+d(z, y)$ for all $x, y, z \in X$.

Then the function $d$ is called dislocated quasi-metric on $X$ and the pair $(X, d)$ is called a dislocated quasi-metric space( in short dq-metric space).

In addition, if $d$ satisfies

(d3) $d(x, y)=d(y, x)$ for all $x, y \in X$,

then $(X, d)$ is called a dislocated metric space (d-metric space in short).

Throughout this paper $(X, d)$ will denote a dq-metric space.
Definition 2.[5] A sequence $\left(x_{n}\right)$ dislocated quasi-converges (for short dq-converges) to $x$ in $X$ if

$$
\lim d\left(x_{n}, x\right)=\lim d\left(x, x_{n}\right)=0 .
$$

In this case $x$ is called a dq-limit of $\left(x_{n}\right)$ and we write $\lim x_{n}=x$ in $(X, d)$.

Remark.dq-limits of a dq-convergent sequence in dq-metric space are unique.

Definition 3.[5] A sequence $\left(x_{n}\right)$ in $X$ is called Cauchy (resp. Bicauchy) if for each $\varepsilon>0$ there exists a positive integer $N_{\varepsilon}$ such that for all $m, n \geq N_{\varepsilon}, d\left(x_{m}, x_{n}\right)<\varepsilon$ or $d\left(x_{n}, x_{m}\right)<\varepsilon \quad\left(\right.$ resp. $\left.\max \left\{d\left(x_{n}, x_{m}\right), d\left(x_{m}, x_{n}\right)\right\}<\varepsilon\right)$. $(X, d)$ is called complete $d q$-metric space if every Cauchy sequence in $X$ is a dq-convergent in $X$.

Definition 4.[5] Let $\left(X, d_{1}\right)$ and $\left(Y, d_{2}\right)$ be a dq-metric spaces. Then $f: X \rightarrow Y$ is continuous if for each sequence $\left(x_{n}\right)$ which is $d_{1} q$-convergent to $x_{0}$ in $X$, the sequence $\left(f\left(x_{n}\right)\right)$ is $d_{2} q$-convergent to $f\left(x_{0}\right)$ in $Y$.

Definition 5.A mapping $T: X \rightarrow X$ is called a contraction if

$$
d(T x, T y) \leq \alpha d(x, y)
$$

for all $x, y \in X$ and $0 \leq \alpha<1$. $\alpha$ is called a contracting constant.

\footnotetext{
*Corresponding author e-mail: ssrao.siginam@gmail.com
} 
Definition 6.[4] A mapping $T: X \rightarrow X$ is called a Kannan mapping if

$$
d(T x, T y) \leq \alpha\{d(x, T x)+d(y, T y)\}
$$

for all $x, y \in X$ and $0 \leq \alpha<\frac{1}{2}$.

The following proposition is a natural generalization of result in metric space(See [3]) to dq-metric space.

Proposition 1.If $T$ is a contraction on a dq-metric space $(X, d)$ with contracting constant $\alpha$, then

$\frac{d\left(T^{n} x, T^{n} y\right)+d\left(T^{n} y, T^{n} x\right)}{2} \leq \frac{\alpha^{n}}{1-\alpha^{n}}\left\{\frac{d\left(x, T^{n} x\right)+d\left(T^{n} x, x\right)}{2}+\frac{d\left(y, T^{n} y\right)+d\left(T^{n} y, y\right)}{2}\right\}$

and $0 \leq \frac{\alpha^{n}}{1-\alpha^{n}}<\frac{1}{2}$ for some positive integer $n$. Further, if $d(x, y)=d(y, x)$ for all $x, y \in X$, then $T^{n}$ is a Kannan mapping on $X$ for some $n \in \mathbb{N}$.

Examples 1It is clear that metric spaces and d-metric spaces are dq-metric spaces.

1.Define $d$ on $\mathbb{Q} \times \mathbb{Q}$ by $d(x, y)=|x|$. Then $d$ is a complete dq-metric but not a metric on $X$ and the sequence $\left(\frac{1}{n}\right)_{n \in \mathbb{N}} d q$-converges to 0 .

2.Let $X=\mathbb{N}$ and $d(x, y)=x$ for all $x, y$ in $\mathbb{N}$. Then $(X, d)$ is a complete dq-metric space.

\section{Main Results}

In this section $A$ will denote the set $\{x \in X: d(x, x)=0\}$.

Example 1.The set $A$ in $(X, d)$ of Example 1(1) is $\{0\}$ whereas in Example 1(2) it is empty.

Result 2If $\left(x_{n}\right)$ is a dq-convergent sequence in $X$ with a dq-limit $x$, then $x \in A$.

Proof.Let $x$ be a dq-limit of a sequence $\left(x_{n}\right)$ in $X$. Let $\varepsilon>0$. Then there exists a positive integer $N_{\varepsilon}$ such that for all $n \geq N_{\varepsilon} 0 \leq d(x, x) \leq d\left(x, x_{n}\right)+d\left(x_{n}, x\right)<\varepsilon$. Since $\varepsilon>0$ is arbitrary, $d(x, x)=0$.

Result 3If $A$ is a nonempty subset of complete dq-metric space $X$, then $(A, d)$ is complete subspace of $X$.

Proof.Let $\left(x_{n}\right)$ be a Cauchy sequence in $A$. Since $X$ is a complete, there exists $u \in X$ such that $\left(x_{n}\right)$ dq-converges to $u$ in $X$. By Result $2, u \in A$. Therefore $A$ is complete.

Lemma 1.If we define $D$ on $X \times X$ by $D(x, y)=\frac{d(x, y)+d(y, x)}{2}$, then

$1 . D$ is a d-metric on $X$,

$2 \cdot \lim D\left(x_{n}, x\right)=0$ if and only if $\lim x_{n}=x$ in $(X, d)$,

3.If $A$ is a nonempty set, then $D$ is a metric on $A$,

4.If $(X, d)$ is a complete dq-metric space, then $(X, D)$ is a complete d-metric space.
Proof.The proof of (1),(2) and (3) are clear.

Let $\left(x_{n}\right)$ be a Cauchy sequence in $(X, D)$ and let $\varepsilon>0$. Then there exists a positive integer $N_{\varepsilon}$ such that $D\left(x_{n}, x_{m}\right)<\frac{\varepsilon}{2}$ whenever $n, m \geq N_{\varepsilon}$. Thus for $n, m>$ $N_{\varepsilon}, \min \left\{d\left(x_{n}, x_{m}\right), d\left(x_{m}, x_{n}\right)\right\} \leq d\left(x_{n}, x_{m}\right)+d\left(x_{m}, x_{n}\right)<\varepsilon$ and hence $\left(x_{n}\right)$ is a Cauchy sequence in $(X, d)$. Since $(X, d)$ is complete, there exists $x$ in $X$ such that $\left(x_{n}\right)$ dq-converges to $x$. By (2), $\lim D\left(x_{n}, x\right)=0$ and hence $(X, D)$ is a complete $\mathrm{d}$-metric space.

Lemma 2.Let $f$ be a contraction on $X$ with a contracting constant $\lambda$. Then for each $x \in X$ the sequence $\left(f^{n} x\right)$ is a Cauchy sequence in $X$.

Proof.Let $x \in X$ and $x_{n}=f^{n} x$. Then

$d\left(x_{n}, x_{n+1}\right)=d\left(f^{n} x, f^{n+1} x\right) \leq \lambda d\left(f^{n-1} x, f^{n} x\right) \leq \ldots \leq$ $\lambda^{n} d(x, f x)$. Now

$$
\begin{aligned}
d\left(x_{n}, x_{n+k}\right) & \leq d\left(x_{n}, x_{n+1}\right)+d\left(x_{n+1}, x_{n+2}\right)+\ldots . .+d\left(x_{n+k-1}, x_{n+k}\right) \\
& \leq\left(\lambda^{n}+\lambda^{n+1}+\ldots+\lambda^{n+k-1}\right) d(x, f x) \\
& <\frac{\lambda^{n}}{1-\lambda} d(x, f x) .
\end{aligned}
$$

Assume that $d(x, f x)>0$. Letting $n \rightarrow \infty,\left(x_{n}\right)$ is a Cauchy sequence. Also, if $d(x, f x)=0$, then $d\left(x_{n}, x_{n+p}\right)=0$ for all $n, p>0$ and hence $\left(x_{n}\right)$ is a Cauchy sequence in $X$.

Theorem 4.Let $f$ be a contraction on a complete $d q$-metric space $X$ with contracting constant $\lambda$. Then $f$ has a unique fixed point in $X$.

Proof.Let $x \in X$ and $x_{n}=f^{n} x$. By Lemma 2, the sequence $\left(f^{n} x\right)$ is a Cauchy sequence in $X$. Since $X$ is complete, there exists $u \in X$ such that $\lim f^{n} x=u$. By Result $2, u \in A$ and hence $A$ is nonempty. Define $D(x, y)=\frac{d(x, y)+d(y, x)}{2}$ for all $x, y \in X$, then by Lemma 1 and Result $3,(A, D)$ is a complete metric space. Let $x \in A$. Then $d(f(x), f(x)) \leq$ $\lambda d(x, x)=0$ and hence $f(A) \subseteq A$. Also,

$D(f x, f y)=\frac{d(f x, f y)+d(f y, f x)}{2} \leq \lambda \frac{d(x, y)+d(y, x)}{2}=\lambda D(x, y)$.

Therefore $f$ is a contraction on $(A, D)$. Hence by Banach contraction principle for metric spaces, $f$ has a unique fixed point $x$ in $A$.

If $y$ is a fixed point of $f$ in $X$, then $d(x, y)=d(f x, f y) \leq \lambda d(x, y)$. Since $0 \leq \lambda<1$, $d(x, y)=0$. By symmetry, $d(y, x)=0$. Therefore $x=y$ and $f$ has a unique fixed point in $X$.

In [4] C.T. Aage and J. N. Salunke, proved that every continuous Kannan mapping $T$ on a complete dq-metric space has a unique fixed point. The following result shows that the assumption of continuity can be dropped to obtain the theorem under a less restrictive contractive condition

Theorem 5.If $T$ is mapping on a complete dq-metric space $(X, d)$ into itself and if there is a constant $\alpha$ such that $0 \leq$ $\alpha<\frac{1}{2}$ and

$$
d(T x, T y) \leq \alpha\{d(x, T x)+d(y, T y)\},
$$

for all $x, y \in X$, then $T$ has a unique fixed point in $X$. 
Proof.Let $x \in X$ and write $x_{n}=T^{n} x$. Then $d\left(x_{1}, x_{2}\right)=d\left(T x, T x_{1}\right) \leq \alpha\left\{d(x, T x)+d\left(x_{1}, T x_{1}\right)\right\}$

$\Rightarrow(1-\alpha) d\left(x_{1}, x_{2}\right) \leq \alpha d\left(x, x_{1}\right)$

$\Rightarrow d\left(x_{1}, x_{2}\right) \leq \frac{\alpha}{(1-\alpha)} d\left(x, x_{1}\right)$

An inductive argument yields the inequality

$$
d\left(x_{n}, x_{n+1}\right) \leq \lambda^{n} d\left(x, x_{1}\right)
$$

where $\lambda=\frac{\alpha}{(1-\alpha)}$.

\section{Now}

$$
\begin{aligned}
d\left(x_{n}, x_{n+k}\right) & \leq d\left(x_{n}, x_{n+1}\right)+d\left(x_{n+1}, x_{n+2}\right)+\ldots .+d\left(x_{n+k-1}, x_{n+k}\right) \\
& \leq\left(\lambda^{n}+\lambda^{n+1}+\ldots+\lambda^{n+k-1}\right) d\left(x, x_{1}\right) \\
& <\frac{\lambda^{n}}{1-\lambda} d\left(x, x_{1}\right) .
\end{aligned}
$$

Since $0 \leq \lambda<1,\left(x_{n}\right)$ is a Cauchy sequence and since $X$ is complete there exists a $u \in X$ such that $\lim _{n \rightarrow \infty} d\left(x_{n}, u\right)=$ $\lim _{n \rightarrow \infty} d\left(u, x_{n}\right)=0$.

Now we show that $u$ is a fixed point of $T$.

$$
\begin{aligned}
d(u, T u) & \leq d\left(u, x_{n}\right)+d\left(x_{n}, T u\right) \\
& =d\left(u, x_{n}\right)+d\left(T x_{n-1}, T u\right) \\
& \leq d\left(u, x_{n}\right)+\alpha\left\{d\left(x_{n-1}, x_{n}\right)+d(u, T u)\right\} \\
& \leq d\left(u, x_{n}\right)+\alpha d(u, T u)+\alpha \lambda^{n-1} d\left(x, x_{1}\right)
\end{aligned}
$$

$\Rightarrow 0 \leq d(u, T u) \leq \frac{1}{1-\alpha} d\left(u, x_{n}\right)+\lambda^{n} d\left(x, x_{1}\right)$. Letting $n \rightarrow$ $\infty$, we get $d(u, T u)=0$. Now

$$
\begin{aligned}
d(T u, u) & \leq d\left(T u, x_{n}\right)+d\left(x_{n}, u\right) \\
& =d\left(T u, T x_{n-1}\right)+d\left(x_{n}, u\right) \\
& \leq \alpha\left\{d(u, T u)+d\left(x_{n-1}, x_{n}\right)\right\}+d\left(x_{n}, u\right)
\end{aligned}
$$

$d(T u, u) \leq \alpha d\left(x_{n-1}, x_{n}\right)+d\left(x_{n}, u\right)$ since $d(u, T u)=0$. Letting $n \rightarrow \infty$, we get $d(T u, u)=0$. Therefore, $d(T u, u)=d(u, T u)=0$ and hence $T u=u$.

Uniqueness: If $a$ is a fixed point of $T$, then $d(a, a)=d(T a, T a) \leq \alpha\{d(a, T a)+d(a, T a)\}=$ $\alpha\{d(a, a)+d(a, a)\}$ which implies that $(1-2 \alpha) d(a, a) \leq 0$. Since $0 \leq \alpha<\frac{1}{2}, d(a, a)=0$. If $a, b$ are fixed points of $T$, then $d(a, b)=d(T a, T b) \leq$ $\alpha\{d(a, T a)+d(b, T b)\}=\alpha\{d(a, a)+d(b, b)\}=\overline{0}$. Therefore $d(a, b)=0$. By symmetry, $d(b, a)=0$. Hence $a=b$.

\section{References}

[1] A. Isufati, "Fixed point theorems in Dislocated quasi-metric spaces, Applied Mathematical Sciences, 4, 217-223 (2010).

[2] B. E. Rhoades, A Comparison of Various Definitions of Contractive mappings, Trans. Amer.Math.Soc. 266, 257290 (1997).

[3] B. Fischer, Mappings on Metric spaces,Acta. Math. Acad. Sci. Hung., 32, 283-285 (1976).
[4] C. T. Aage, J. N. Salunke, The Results on Fixed points in Dislocated and Dislocated quasi-metric space, Applied Mathematical Sciences, 2, 2941-2948 (2008).

[5] F. M. Zeyada, G. H. Hassan, M. A. Ahmed, A Generalization of a Fixed point theorem due to Hitzler and Seda in Dislocated Quasi-Metric Spaces., The Arabian Journal for Science and Engineering, 31, 111-114 (2005).

[6] J. J. M. M. Rutten, Elements of Generalized ultrametric domain theory, Theoretic Comput. Sci, 170, 349-381 (1996).

[7] P. Hitzler, A. K. Seda, Dislocated Topologies, Journal of Electrical Engineering, 51, 3-7 (2000).

[8] R. Kannan, Some results on fixed points, Bull. Cal. math. soc., 60 , 71-76 (1968). 


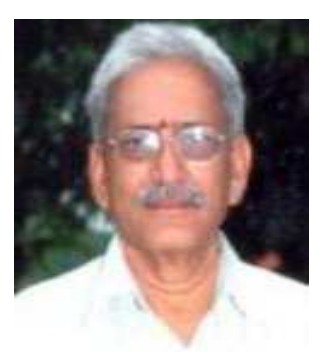

I. Ramabhadra Sarma, (Rtd) Professor of Mathematics, Department of Mathematics, Acharya Nagarjuna University, India. His area of interest is Functional Analysis, Topology, Measure Theory and Statistics. He has published research papers in reputed international journals of mathematics and statistics and guided students to Ph.D and M.Phil degree. He received his Ph.D degree entitled Means with Values in a Banach Lattice and Some Results of Tensor Products (January 1, 1977) from University of Nebraska-Lincoin. $\mathrm{He}$ is referee and editor of several international journals in the frame of pure and applied mathematics and authored Mathematics textbooks.

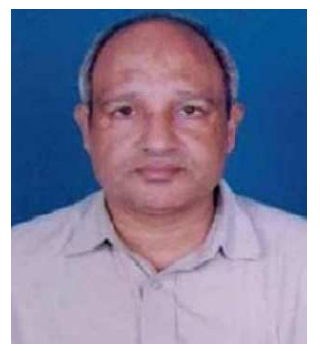

$\begin{array}{lcr} & \text { J. Madhusudana } \\ \text { Rao, } & \text { presently } & \text { working } \\ \text { as a } & \text { Director (Academics } \\ \text { and } & \text { Research), } & \text { Vijaya }\end{array}$

Engineering College,

Khammam, Andhra Pradesh, India. $\mathrm{He}$ has 28 years of teaching and research experience in mathematics. His area of interests is

Functional analysis, fixed point theory and allied topics. $\mathrm{He}$ has published several research papers in national and international journal in pure mathematics.

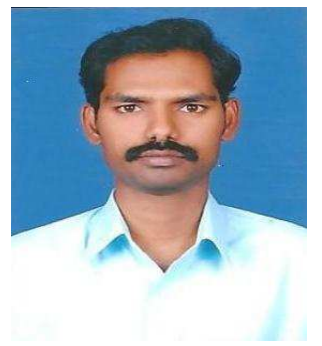

S. Sambasiva Rao, Assistant Professor of Mathematics, SVS Institute of Technology, Warangal, India and pursing his Ph.D. under the guidance of Prof. I. Ramabhadra sarma. He has 12 years of teaching and research experience. He received his Master degree in Mathematics from Acharya Nagarjuna university and M.Phil from Madurai Kamaraj university, India. His area of interest is Topology, Fixed point theory and number theory. He has two publications to his credit. 